\title{
Associations between the measures of physical function, risk of falls and the quality of life in haemodialysis patients: a cross-sectional study
}

\author{
Karsten Vanden Wyngaert ${ }^{1}$, Amaryllis H. Van Craenenbroeck ${ }^{2,3}$, Sunny Eloot ${ }^{4}$, Patrick Calders ${ }^{1 *} \mathbb{D}$, Bert Celie $^{1}$,
} Els Holvoet ${ }^{4}$ and Wim Van Biesen ${ }^{4}$

\begin{abstract}
Background: Impaired physical function due to muscle weakness and exercise intolerance reduces the ability to perform activities of daily living in patients with end-stage kidney disease, and by consequence, Health-Related Quality of Life (HRQOL). Furthermore, the risk of falls is an aggregate of physical function and, therefore, could be associated with HRQoL as well. The present study examined the associations between objective and subjective measures of physical function, risk of falls and HRQoL in haemodialysis patients.
\end{abstract}

Methods: This cross-sectional multicentre study included patients on maintenance haemodialysis. Physical function (quadriceps force, handgrip force, Sit-to-Stand, and six-minute walking test), the risk of falls (Tinetti, FICSIT-4, and dialysis fall index) and HRQoL (PROMIS-29 and EQ-5D-3 L) were measured and analysed descriptively, by general linear models and logistic regression.

Results: Of the 113 haemodialysis patients (mean age $67.5 \pm 16.1,57.5 \%$ male) enrolled, a majority had impaired quadriceps force (86.7\%) and six-minute walking test (92\%), and an increased risk of falls (73.5\%). Whereas muscle strength and exercise capacity were associated with global HRQoL $\left(R^{2}=0.32\right)$ and the risk of falls, the risk of falls itself was related to psycho-social domains $\left(R^{2}=0.11\right)$ such as depression and social participation, rather than to the physical domains of HRQoL. Objective measures of physical function were not associated with subjective fatigue, nor with subjective appreciation of health status.

Conclusions: More than muscle strength, lack of coordination and balance as witnessed by the risk of falls contribute to social isolation and HRQoL of haemodialysis patients. Mental fatigue was less common than expected, whereas, subjective and objective physical function were decreased.

Keywords: End-stage kidney disease, Physical function, Risk of falls, Haemodialysis, Quality of life

\section{Background}

Exercise intolerance, defined as decreased physical ability to perform activities requiring muscle strength and cardiovascular capacity, is common in patients on haemodialysis (HD) [1]. Furthermore, the combination of cardiovascular comorbidities and changes in muscle characteristics such as mitochondrial dysfunction lead

\footnotetext{
* Correspondence: Patrick.calders@ugent.be

'Department of Rehabilitation Sciences, Faculty of Medicine and Health Sciences, Ghent University, Corneel Heymanslaan 10, 9000 Ghent, Belgium Full list of author information is available at the end of the article
}

to reduced oxidative contribution resulting in aerobic exercise intolerance $[2,3]$. In addition, catabolic processes, inflammation and malnutrition further contribute to muscle wasting and physical inactivity in HD patients $[4,5]$.

Next to decreased muscle strength, uremic polyneuropathy, autonomic dysfunction, hypotensive episodes, and polypharmacy contribute to an increased risk of falls as well, resulting in a 4.4 times higher risk for hip fractures in HD patients compared to age-matched healthy control subjects $[6,7]$. The risk of falls could be seen as 
an aggregate marker of physical function. Both reduced maximal oxygen uptake and an increased risk of falls are predictive for morbidity and mortality in patients on HD [8].

A reduced exercise capacity and muscle strength affects the ability to perform activities of daily living (ADL) [9], and hence potentially, the overall HealthRelated Quality of Life (HRQoL) [8, 10]. However, the impact of the risk of falls on HRQoL on top of muscle weakness and exercise capacity has not yet been examined in HD patients. Nonetheless, this is an important question as it could result in different training and rehabilitation needs for this population [8].

Furthermore, fatigue is the common complication in patients on HD (73-91\%) [11, 12] and was recently identified as the most important outcome by all stakeholders [13]. It is characterized as both a physical and psychological symptom, and has a multi-faced aetiology, ranging from plain physical exertion over physical performance and energy management to depression [14]. The association between fatigue and the components of HRQoL is potentially bilateral, as the lack of energy due to reduced physical capacity might induce depression and mood disorders, or it could be the other way around [15]. Again, better insight into the association between subjective fatigue and objective physical function is important, as it can steer interventional strategies.

We hypothesised that both psychosocial and physical domains of HRQoL are associated with objective measures of physical function in patients on HD.

The purpose of this cross-sectional study was to examine the association between the objective and subjective measures of physical function, the risk of falls and subcategories of HRQoL in prevalent HD patients.

\section{Methods}

\section{Participants and study design}

Patients on maintenance HD, who were included in a larger study (registration number on clinicaltrial.gov: NCT03910426), in two main dialysis centres were screened for eligibility between December 2016 and March 2018. These dialysis centres included five different dialysis units (two high-care and five low-care dialysis units) distributed throughout five different public hospitals. Exclusion criteria were the following: age $<18$ years, pregnancy, active inflammation, malignancy, cognitive disorders, inadequate motor and verbal responses to verbal commands and questions, and recent $(<6$ months) surgical musculoskeletal interventions. Patients with physical inabilities (e.g. wheelchair bound or amputations) were given the worst possible score for those examinations they failed to complete.
The study complies with the Declaration of Helsinki, was approved by the local ethics committees (project number Ghent EC B670201525559 and Antwerp EC B300201422642), and written informed consent was obtained.

\section{Anthropometric measures and characteristics}

Baseline clinical data and anthropometric measures were obtained, and pre- and post-dialysis mean arterial pressures (MAP) were calculated as diastolic blood pressure $+1 / 3$ (systolic blood pressure - diastolic blood pressure). Blood pressures were measured with a single measurement at the upper-arm opposite to the vascular access.

\section{Physical examinations}

The sequence of the different tests was randomized using opaque envelopes. Muscle strength examinations took place before dialysis sessions, while the measurements of functional exercise capacity and the risk of falls were examined either before dialysis or in patients' home setting on non-dialysis days. A minimum 3-min pause between tests was respected and utmost care was taken that the different assessments of functional exercise capacity were not directly consecutive.

\section{Muscle strength}

A handheld dynamometer (Microfet; Biometrics, Almere, the Netherlands) was used to evaluate quadriceps isometric peak torque in a sitting position with knees and hips $90^{\circ}$ flexed [16]. Manual resistance with fixation of the dynamometer to the anterior tibia of the dominant leg just proximal to the malleoli was applied by a researcher for $5 \mathrm{~s}$ [17]. Handgrip force of the hand opposite to the vascular access was measured using a JAMAR Hydraulic Hand Dynamometer according to the American Society of Hand Therapists guidelines [18]. Patients were seated with their elbow $90^{\circ}$ flexed next to their body, wrist in neutral position and were asked to perform a maximal isometric contraction for $5 \mathrm{~s}$ [19].

The best out of 3 attempts was expressed as absolute value and as the percentage of the predicted value based on age and gender $[16,20]$.

\section{Physical functioning}

The six-minute walking test (6MWT) is a functional examination of exercise capacity and was performed following the American Thoracic Society guidelines [21]. Patients were instructed to walk as fast as possible for 6 min, walking aids were allowed and recorded. Results were expressed as absolute value and as percentage to the predicted value [22]. A $350 \mathrm{~m}$ cut-off point was used, as this indicates a worse prognosis and higher mortality in populations comparable to patients on HD [23, 24]. 


\section{The risk of falls}

For assessment of the risk of falls, a combination of physical testing, scoring lists and demographic data was used in a slightly adapted version of the Dialysis Fall Risk Index (DFRI, Table 1) [25]. With regard to the original DFRI, the following adaptations were made: (1) a $2.9 \mathrm{mg} / \mathrm{dl}$ instead of $1.0 \mathrm{mg} / \mathrm{dl}$ cut-off point for Creactive protein; (2) mini-nutritional assessment indication scores were used as an alternative for the Geriatric Nutritional Risk Index [26]; (3) 6MWT with an additional $300 \mathrm{~m}$ cut-off point for an increased risk of falls replaced the ' 4 meter time to walk' test; and (4) the 'inquiry about fall' section was replaced by the Tinetti test [27].

The Tinetti test is considered the gold standard for examining fall-related gait dysfunctions based on 7 items: initiation of gait, step length and height, step symmetry, step continuity, distinguished path, trunk and walking stance. Patients scoring $<11$ on 12 on the Tinetti test are considered at a high risk of falls [28].

The Frailty and Injuries Cooperative Studies of Intervention Technique-4 (FICSIT) was used to examine static balance (on time) based on seven positional challenges; i.e. eyes open and closed with feet closely together, semi-tandem and full tandem stand, and standing on the dominant leg with eyes open [29]. No consistent cut-off values were found in the literature.

The five repetition Sit-to-Stand (STS) was used to assess the risk of falls as well as functional lower limb muscle strength [30]. Patients were instructed to get from a sitting to a standing position for 5 times as rapidly as possible with their arms folded across the chest [31]. A cut-off value of $\geq 15 \mathrm{~s}$ is associated with an increased risk of falls [32].

\section{Health-related quality of life}

Using a Dutch version of the EQ-5D-3 L from the Euro QOL Group and the PROMIS-29 v2.0, patients were surveyed by a study nurse during the dialysis session closest to the physical examinations. The EQ5D comprises five dimensions: mobility, self-care, usual activities, pain discomfort and anxietydepression which are scored on a 3-point Likert scale [33]. The PROMIS questionnaire assesses following seven domains using four questions for each domain, which are scored from 1 to 5: depression, anxiety, physical function, pain interference, fatigue, sleep disturbance and ability to participate in social roles and activities. The PROMIS has been validated in patients with chronic diseases, albeit, to our knowledge, not in patients with end-stage kidney disease [34, 35]. However, as it is considered a generic scale of HRQoL, it should deliver reliable results as well.

\section{Statistical analysis}

IBM Statistical Package for the Social Sciences version 24 was used for all statistical analyses. Descriptive analysis reports mean \pm standard deviation (SD), median and interquartile range [25th; 75th percentage] or number and percentage when appropriate. The data of the PROMIS questionnaire are reported as T-scores based on a representative sample of the US population. Reference values of EQ-5D are based on a Belgian population of similar age and gender distribution [36]. The lower limit of normal (LLN) for the quadriceps and handgrip force, and $6 \mathrm{MWT}$ was set on $80 \%$ of the predicted value. Patients unable to perform the 6MWT and STS were scored as ' $0 \mathrm{~m}$ ' and '> 50 seconds' respectively. Patients were distributed into three groups of global physical performance on regard of impairments in neither, only one or both the 6MWT and DFRI (i.e. good, impaired or severely impaired physical performance groups respectively). Data between groups were compared with univariate analysis of variance and the post hoc Scheffe's test. General linear models and logistic regressions were applied to evaluate the association between the parameters of interest.

\section{Results}

A total of 122 patients were enrolled in this study. Nine patients with missing data were excluded, giving a response rate of $93 \%$, albeit six patients for missing data on QoL questionnaires and three patients on measures of physical function. There were no major differences between the excluded and included subjects.

Table 2 presents data on patients' characteristics and the parameters of interest. In this cohort $(57.5 \%$ male, age $68 \pm 16$ years) cardiovascular disease was the most common comorbidity (74.3\%) followed by diabetes (46.0\%) and musculoskeletal complications (e.g. amputations and gout, $44.2 \%)$. In general, lower physical function and health utility than a presumed healthy, agematched population were noted (see Additional file 1). Subjective difficulties with mobility and usual activities were reported by 52.2 and $55.8 \%$ of the cohort in the EQ-5D (Fig. 1). Decreased (> 1SD) appreciation of physical function and social participation according to the PROMIS was reported by 50.4 and $30.1 \%$ of the cohort. Furthermore, a minority reported significant complaints of pain $(27.4 \%)$, depression (23.9\%), fatigue (18.6\%), anxiety $(15.0 \%)$ and sleep disturbances (12.4\%).

Impairments in physical function were especially pronounced in lower limb muscle strength (86.7 and $69 \%$ had impaired values in absolute and functional quadriceps strength respectively) and in functional exercise capacity (92\% scored below the LLN of the $6 \mathrm{MWT}$, Fig. 2). A majority of studied patients scored below the 6MWTs' clinically relevant cut-off point of 
Table 1 Dialysis risk of falls index

\begin{tabular}{|c|c|c|c|c|}
\hline Topic & Check & & & Score \\
\hline \multirow[t]{3}{*}{ Age } & $\geq 80$ years old & & & \\
\hline & Yes & & & 1.5 \\
\hline & No & & & 0 \\
\hline \multirow[t]{3}{*}{ Serum C-reactive Protein } & $\geq 3.0 \mathrm{mg} / \mathrm{dL}$ & & & \\
\hline & Yes & & & 2.0 \\
\hline & No & & & 0 \\
\hline \multirow[t]{3}{*}{ Risk for malnutrition } & $<24$ on 30 & & & \\
\hline & Yes & & & 0.5 \\
\hline & No & & & 0 \\
\hline \multirow[t]{21}{*}{ Physical examinations } & $\underline{\text { Standing balance }}$ & & & \\
\hline & - Side-by-side stand & & & \\
\hline & $10 s$ & 1 & & \\
\hline & $<10 \mathrm{~s}$ & 0 & & \\
\hline & - Semi-tandem stand & & & \\
\hline & $10 s$ & 1 & & \\
\hline & $<10 s$ & 0 & & \\
\hline & - Full-tandem stand & & & \\
\hline & $10 \mathrm{~s}$ & 2 & $<8$ points & 2.5 \\
\hline & $3-9.9 \mathrm{~s}$ & 1 & & \\
\hline & $<3 s$ & 0 & 9-10 points & 2.0 \\
\hline & $6 \mathrm{MWT}$ & & & \\
\hline & $>350 \mathrm{~m}$ & 4 & $11-12$ points & 0 \\
\hline & $300-350 m$ & 2 & & \\
\hline & $<300 \mathrm{~m}$ & 0 & & \\
\hline & $\underline{\mathrm{STS}}$ & & & \\
\hline & $<11.19 \mathrm{~s}$ & 4 & & \\
\hline & $11.20-13.69 s$ & 3 & & \\
\hline & $13.70-16.69 \mathrm{~s}$ & 2 & & \\
\hline & $16.70-49.99 s$ & 1 & & \\
\hline & $>50$ s or impossible & 0 & & \\
\hline \multirow[t]{3}{*}{ Handgrip force } & Male $<26 \mathrm{~kg}$, female $<18 \mathrm{~kg}$ & & & \\
\hline & Yes & & & 1.5 \\
\hline & No & & & 0 \\
\hline \multirow[t]{3}{*}{ Intra-dialytic hypotension } & MAP decrease $>9.99 \mathrm{mmHg}$ & & & \\
\hline & Yes & & & 1.5 \\
\hline & No & & & 0 \\
\hline \multirow[t]{3}{*}{ Risk of falls assessment } & Tinetti $<11$ on 12 points & & & \\
\hline & Yes & & & 2.5 \\
\hline & No & & & 0 \\
\hline Total score & & & & $/ 12$ \\
\hline
\end{tabular}

Abbreviations: $6 M W T$ six-minute walking test, MAP mean arterial pressure, STS sit-to-stand test

$350 \mathrm{~m}(63.7 \%)$ and was rated with an increased risk of falls $(73.5 \%)$. Noteworthy, the measures of the risk of falls were determined by objective measures of physical function $(\mathrm{OR}=0.750)$, but were associated with functional exercise capacity more than muscle strength (see Additional file 2). 
Table 2 Patients' characteristics and parameters of interest

\begin{tabular}{|c|c|}
\hline Variable & $n=113$ \\
\hline Age (years) & $68 \pm 16$ \\
\hline Male sex & $65(57.5)$ \\
\hline $\mathrm{BMI}\left(\mathrm{kg} / \mathrm{m}^{2}\right)$ & $26.1 \pm 5.4$ \\
\hline Dialysis vintage (months) & $22.5[10.3 ; 49.8]$ \\
\hline$\triangle \mathrm{MAP}(\mathrm{mmHg})$ & $0.17 \pm 15.5$ \\
\hline MAP pre-dialysis (mmHg) & $89.7 \pm 15.3$ \\
\hline MAP post-dialysis (mmHg) & $89.3 \pm 17.8$ \\
\hline \multicolumn{2}{|l|}{ Aetiology of CKD } \\
\hline Glomerulonephritis & $19(16.8)$ \\
\hline Hematologic malignancies & $5(4.4)$ \\
\hline Interstitial nephritis & $13(11.5)$ \\
\hline Diabetic nephropathy & $30(26.5)$ \\
\hline Hypertension, angiosclerosis or unknown & $40(35.4)$ \\
\hline ADPKD & $6(5.4)$ \\
\hline \multicolumn{2}{|l|}{ Comorbidities } \\
\hline Diabetes & $52(46.0)$ \\
\hline CVD & $84(74.3)$ \\
\hline Neuropathy & $32(28.3)$ \\
\hline Retinopathy & $36(31.9)$ \\
\hline Respiratory complications & $28(24.8)$ \\
\hline Musculoskeletal complications & $50(44.2)$ \\
\hline Hepatopathy & $20(17.7)$ \\
\hline \multicolumn{2}{|l|}{ Quadriceps force } \\
\hline Absolute value (N) & $180 \pm 75$ \\
\hline Relative value (\% to predicted) & $53.8 \pm 17.8$ \\
\hline \multicolumn{2}{|l|}{ Handgrip force } \\
\hline Absolute value (kg) & $28.8 \pm 11.1$ \\
\hline Relative value (\% to predicted) & $91.7 \pm 30.7$ \\
\hline DFRI (/12) & $5.9 \pm 3.0$ \\
\hline Q1 & $0-3.5$ \\
\hline Q2 & $4-6.5$ \\
\hline Q3 & $7-8.5$ \\
\hline Q4 & $9-12$ \\
\hline Tinetti (/12) & $11.0[5.5 ; 12.0]$ \\
\hline Sit-to-Stand (s) & $23.0[12.0 ; 50.0]$ \\
\hline FICSIT (/28) & $15.0[8.0 ; 21.0]$ \\
\hline \multicolumn{2}{|l|}{$6 \mathrm{MWT}$} \\
\hline Absolute value (m) & $236[67 ; 397]$ \\
\hline Relative value (\% to predicted) & $44.1[12.7 ; 60.3]$ \\
\hline \multicolumn{2}{|l|}{ EQ-5D } \\
\hline Utility score & $0.78[0.41 ; 0.90]$ \\
\hline Reference values based on age/sex & $0.89 \pm 0.01$ \\
\hline VAS score (max 100) & $58.8 \pm 18.9$ \\
\hline Reference values based on age/sex & $78.3 \pm 23.5$ \\
\hline
\end{tabular}

Table 2 Patients' characteristics and parameters of interest (Continued)

\begin{tabular}{ll}
\hline Variable & $n=113$ \\
\hline PROMIS (T-scores) & \\
Depression & $51.2 \pm 9.4$ \\
Anxiety & $49.0 \pm 9.0$ \\
Physical function & $39.7 \pm 11.1$ \\
Pain interference & $51.1 \pm 9.8$ \\
Fatigue & $50.6 \pm 10.1$ \\
Sleep disturbance & $48.1 \pm 9.2$ \\
Participation in social roles and activities & $48.2 \pm 10.0$ \\
\hline
\end{tabular}

Data are reported as mean \pm standard deviation, median [25\%; $75 \%$ ] or as number (percentage) as appropriate

Abbreviations: $A D P K D$ autosomal dominant polycystic kidney disease, $B M I$ body mass index, CVD cardiovascular disease, $D B P$ diastolic blood pressure, $M A P$ mean arterial pressure, $S B P$ systolic blood pressure, $\triangle M A P$ difference preto post-dialytic mean arterial pressure

Although objective measures of physical function were barely associated with estimated personal health status $\left(R^{2}=0.05\right)$, the association between physical function and global HRQoL was modest and mainly driven by the $6 \mathrm{MWT}\left(\mathrm{R}^{2}=0.32\right.$, Table 3$)$. Lower limb muscle strength and functional exercise capacity explained $51.6 \%$ of the variance in subjective physical function based on the EQ-5D. Despite an association between self-care and static balance, non-physical domains of the EQ-5D were not related to physical function (see Additional file 3). Regarding the PROMIS questionnaire, low associations were found between measures of the risk of falls and the appreciation of participation in social roles and activities on the one hand $\left(R^{2}=0.11\right)$, and depression on the other $\left(R^{2}=0.08\right)$. Additionally, a negligible relation was found between quadriceps strength and subjective fatigue. No measures of physical performance were associated with anxiety and sleep disturbance (Table 4).

After classifying patients based on global physical performance, patients with severely impaired functional performance scored worse on all domains of EQ-5D except for anxiety-depression (Fig. 3) and on subjective physical function assessed by PROMIS (see Additional file 1).

\section{Discussion}

This study presents results of subjective and objective measures of physical function and their associations with HRQoL and health utility in patients on maintenance HD. To our knowledge, this is the first study to include risk of falls assessments to explore HRQoL and physical functioning in $\mathrm{HD}$ patients. We confirm a decreased HRQoL and health utility as well as decreased muscle strength and functional exercise capacity, and an increased risk of falls. Both muscle strength and functional exercise capacity were associated with physical domains 


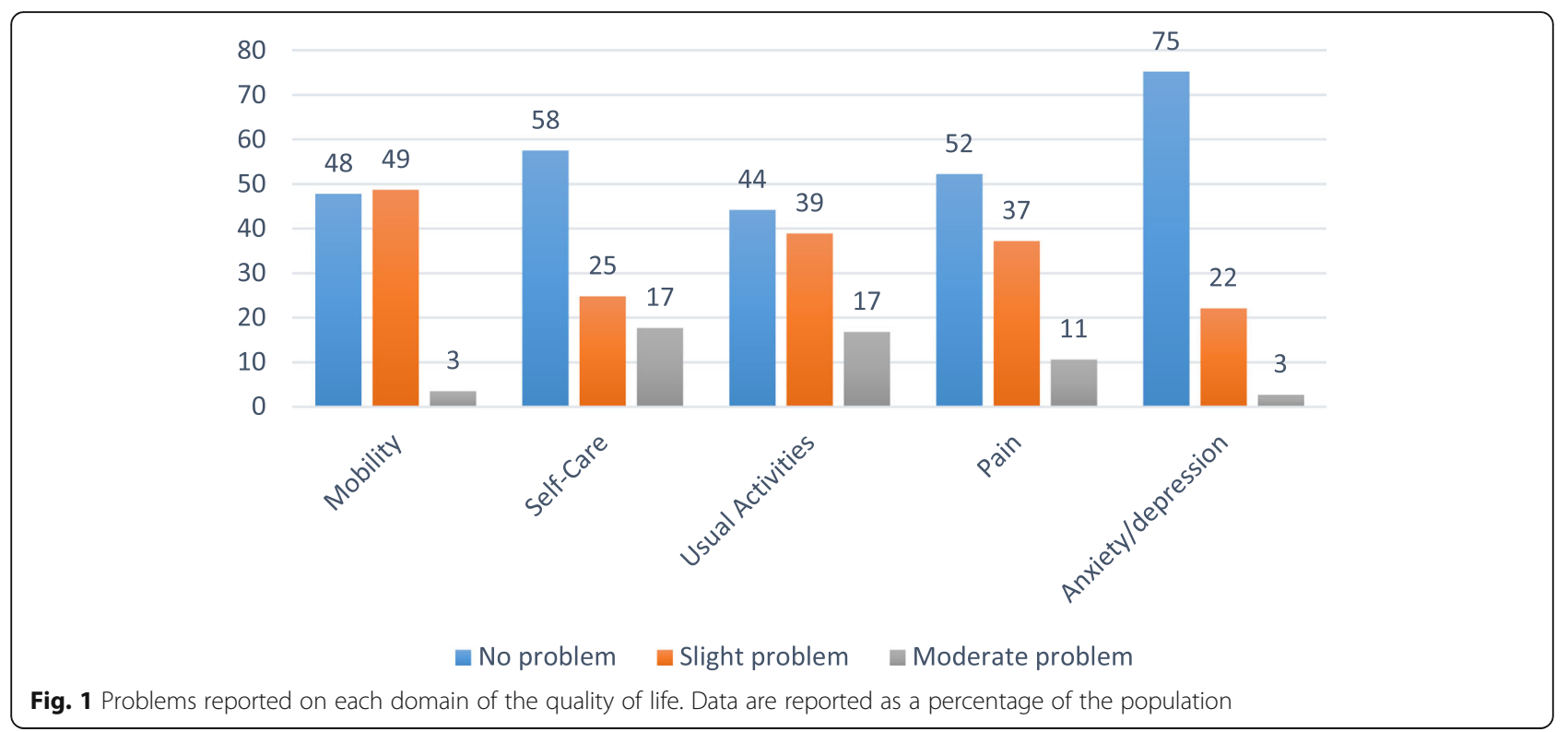

of HRQoL and an increased risk of falls. Remarkably, the risk of falls on itself was identified as a determinant of difficulties on psycho-social well-being (i.e. depression and social isolation) and of objective health utility. Physical rehabilitation of HD patients aiming at improving HRQoL and health utility, should focus on improving coordination and functional capacity rather than purely on muscle strength and exercise capacity.

Adequate physical function is indispensable to be physically active. It requires both sufficient muscle strength and coordination to achieve adequate functional exercise capacity. Hence, impairments in one of those may induce difficulties in mobility and ADL. In addition, the capability to be self-supportive and to participate in society is determined by physical function as well [37]. Therefore, loss of physical function can have a substantial negative impact on psychological well-being, and as a consequence, on objective health utility and HRQoL. As improvements in functional exercise capacity by aerobic exercise training do not induce changes in physical or mental scores of HRQoL in patients on HD [38], a more comprehensive and multidisciplinary approach might be necessary to translate improvements in physical functioning in a positive change of HRQoL.

In uraemia, protein energy wasting and associated muscle weakness are common and relate to physical

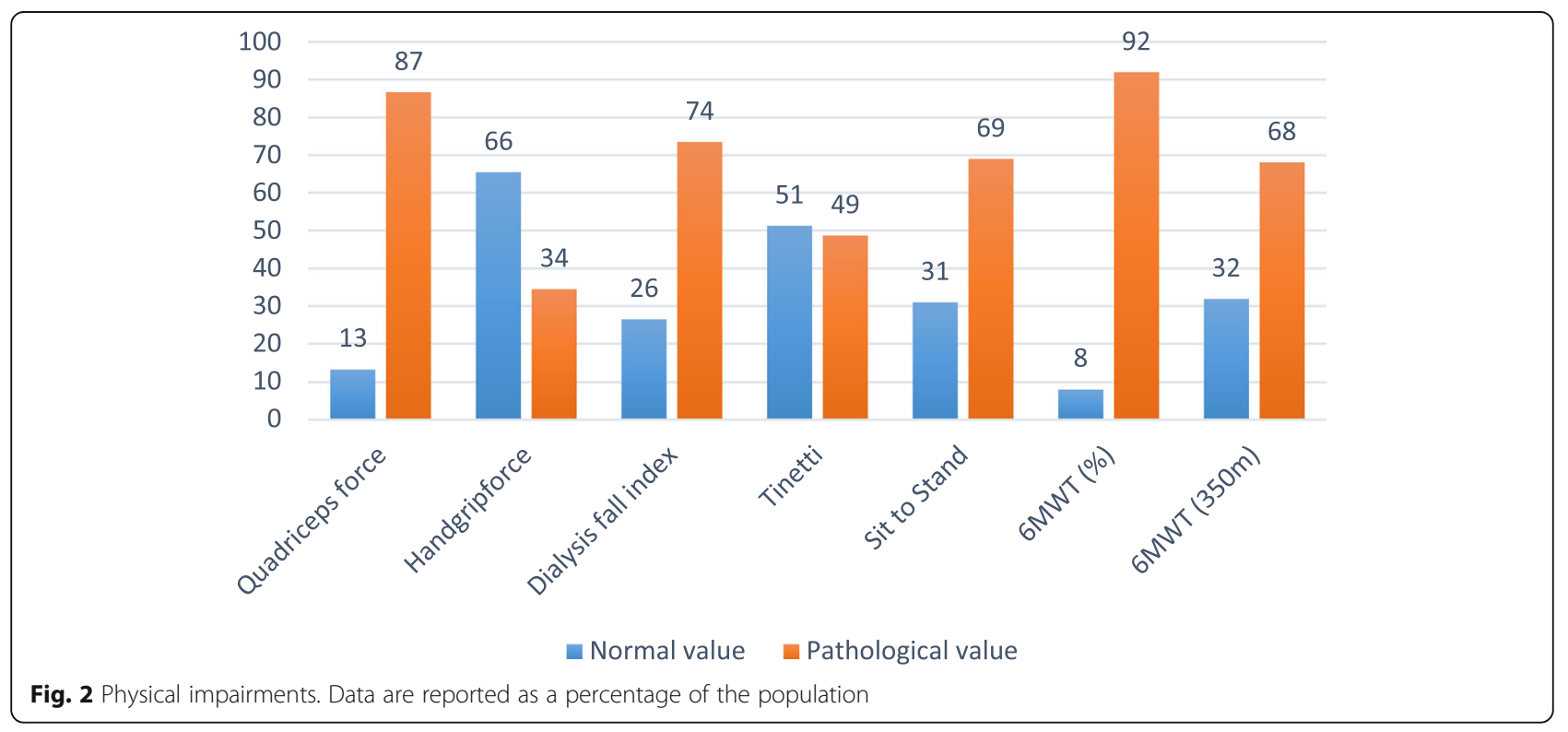


Table 3 Association between the objective measures of physical function and EQ-5D

\begin{tabular}{llllll}
\hline & \multicolumn{2}{l}{ EQ-VAS } & & \multicolumn{2}{l}{ EQ-5D score } \\
\cline { 2 - 3 } & F-value & $p$ & & F-value & $p$ \\
\hline Handgrip force $(\mathrm{kg})$ & $/$ & NS & & 6.52 & 0.012 \\
Sit-to-Stand $(\mathrm{s})$ & 5.11 & 0.015 & & $/$ & NS \\
6MWT $(\mathrm{m})$ & $/$ & $\mathrm{NS}$ & & 16.17 & $<0.001$ \\
R square & 0.053 & & & 0.318 & \\
\hline
\end{tabular}

$\mathrm{R}$ square values are based on a general linear model; factors introduced to the model included absolute quadriceps and handgrip force, Sit-to-Stand test, $6 \mathrm{MWT}$, Tinetti and the dialysis fall index. Abbreviations: $6 M W T$ six-minute walking test

domains of HRQoL [39, 40]. Moreover, uraemia influences both cardiovascular and neurological systems, resulting in decreased exercise capacity and coordination [41]. These systems interact closely during functional activities, and it can thus be hypothesized that uraemia impacts functional exercise capacity not only by a decrease in muscle strength but also by decreased coordination.

Loss in proximal muscle strength as well as neuropathy and musculoskeletal comorbidities can lead to acute and chronic loss of postural stability and subsequently a high rate of falls [42]. Additionally, hypotensive episodes, anaemia, polypharmacy and impaired aerobic exercise capacity do not only cause early physical exertion during ADL, but also enhance the risk of falls $[6,25]$. We found that muscle strength and especially functional exercise capacity explained variations in the risk of falls in HD patients. Consequently, an observed relation between the risk of falls and the physical domains of HRQoL could be expected. However, remarkably, the risk of falls related more to psycho-social than physical domains of HRQoL in the present study. As such, falls and an increased risk of falls can deter subjects to continue their outdoor social activities, resulting in changes in means and location of social contact to less stimulating activities (e.g. a phone call rather than a rendezvous point), promoting the risk of impairments in mental health and depression [43]. This hypothesis dovetails nicely with findings from a large Italian study on $227 \mathrm{HD}$ patients that reported improvements in subjective quality of social interaction after an easy accessible physical activity program [44]. The provision of both physical and occupational therapy in HD patients should thus be considered as it could induce higher levels of physical activity, social participation and well-being. Especially prevention is of importance in HD patients as dialysis treatment hampers social integration and physical activity due to its time consuming impact $[37,45]$, and the high prevalence of reduced physical function, physical activity and HRQoL in this population [46, 47].

We found different associations between HRQoL and measures of physical function. Whereas objective HRQoL (EQ-5D score) was determined by absolute muscle strength, the appreciation of health status (EQVAS) showed only an association with functional muscle strength. The finding that patients accord more importance to functional than absolute measures of muscle function aligns with previous results that subjective health utility is associated with the accumulation of symptoms rather than the degree of one single symptom [48]. This discrepancy between objective measures of physical well-being and subjective health status has been addressed in other studies as 'the well-being paradox'. [49]

Regarding fatigue, the PROMIS fatigue summary score is mainly a mental health factor $(r=-0.82)$ than a physical one $(\mathrm{r}=-0.05)$ [50]. Mental fatigue as well as physical fatigue are identified as important complaints in HD patients worldwide. In our study, mental fatigue was scored not different from the general population, whereas impaired subjective physical function was much more expressed (50\%). This suggests that complaints of fatigue in patients on HD are mainly due to subjective physical dysfunction $[11,12]$. Subjective fatigue was associated with lower limb muscle strength.

Our study has some limitations. First, although we measured the risk of falls by multiple assessment tools, we have no history of actual falls. Instead, this study included the DFRI, a risk of falls assessment tool tailored for patients on HD. As this index was only published when our study was already ongoing, some alterations had to be implemented. Although these small adaptations could affect the general reliability compared to the

Table 4 Association between the objective measures of physical function and PROMIS

\begin{tabular}{|c|c|c|c|c|c|c|c|c|c|c|}
\hline \multirow[t]{2}{*}{ Physical measures } & \multicolumn{2}{|c|}{ Depression } & \multicolumn{2}{|c|}{ Physical function } & \multicolumn{2}{|c|}{ Pain interference } & \multicolumn{2}{|l|}{ Fatigue } & \multicolumn{2}{|c|}{ participation in social roles and activities } \\
\hline & F-value & $p$ & F-value & $p$ & F-value & $\mathrm{p}$ & F-value & $\mathrm{p}$ & F-value & $p$ \\
\hline Quadriceps force $(N)$ & / & NS & 10.96 & $<0.001$ & / & NS & 4.83 & 0.03 & / & NS \\
\hline DFRI (/12) & 6.54 & 0.01 & / & NS & / & NS & / & NS & 7.98 & 0.01 \\
\hline 6MWT (m) & / & NS & 42.21 & $<0.001$ & 4.56 & 0.04 & / & NS & / & NS \\
\hline R Square & 0.078 & & 0.516 & & 0.039 & & 0.044 & & 0.111 & \\
\hline
\end{tabular}

$\mathrm{R}$ square values are based on a general linear model; factors introduced to the model included absolute quadriceps and handgrip force, Sit-to-Stand test, $6 \mathrm{MWT}$ Tinetti and the dialysis fall index. Abbreviations: $6 M W T$ six-minute walking test, DFRI dialysis fall risk index 


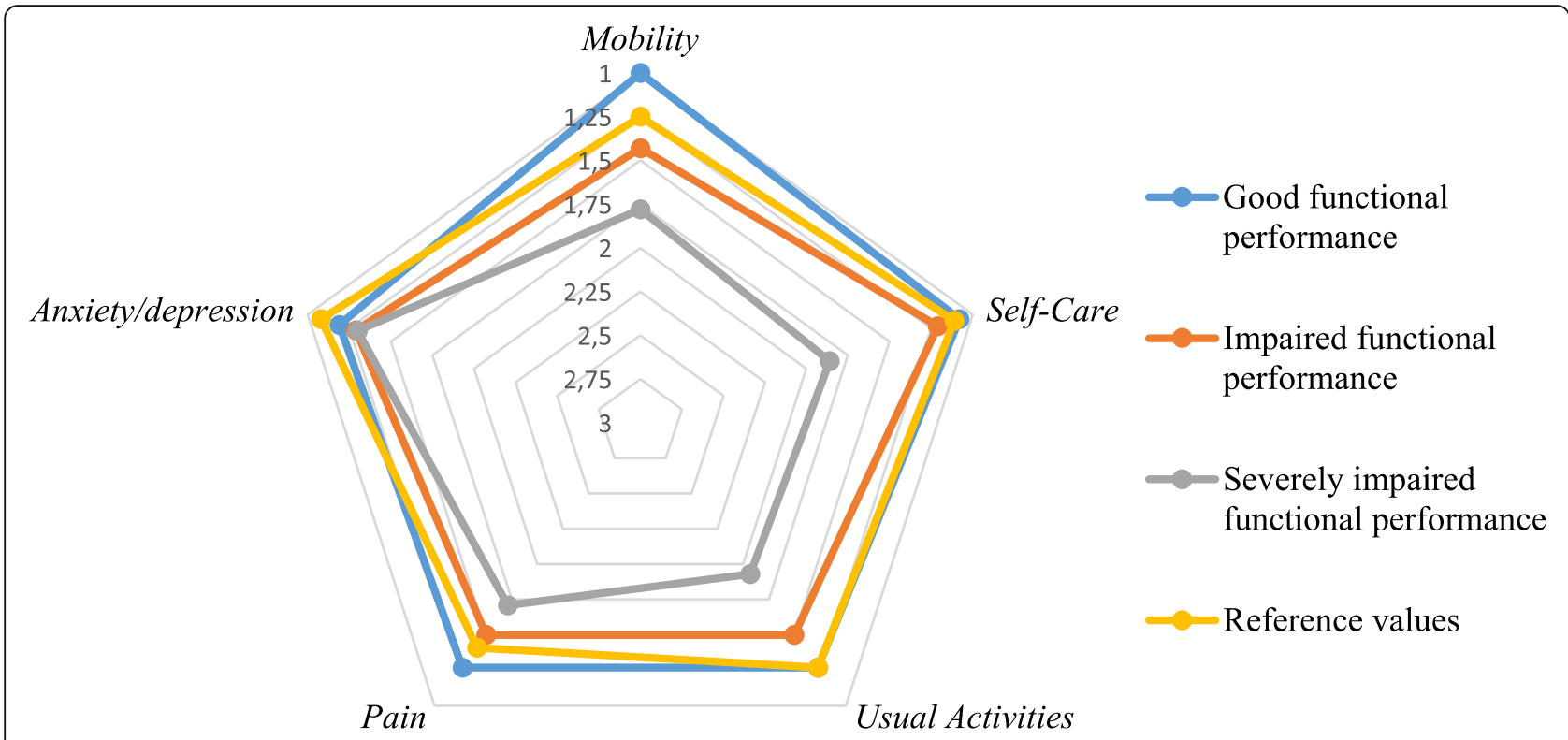

Fig. 3 Radar chart of the dimensions of EQ-5D and functional performance. Increasing scores correspond with increasing difficulty in domains of HRQoL. Patients were allocated to the good, moderate or severely impaired functional performance group based on having no, only one of two or both unfavourable scores on 6MWT and dialysis fall index

original form, we used an equal item reliability to preserve the general reliability as well as possible. Second, the sample size of this study is small and does not exceed the rule of thumb of 20 subjects per variable, which is recommended by Green et al. However, the general linear model presented in this study has a subjects per variable-ratio of 19 and, thus, adequate estimations of regression coefficients, standard errors and confidence intervals can be performed [51].

A strength of this research was that we included HD patients willing to participate, without exclusion of the weakest, and this from multiple dialysis units. Hence, our research provides results that are applicable to the majority of populations on dialysis.

\section{Conclusions}

We conclude that in this cohort of patients on maintenance haemodialysis the objective and subjective physical function, and Health-Related Quality of Life and health utility are decreased and that the risk of falls is increased. Particularly the risk of falls and functional exercise capacity explained large parts of decreased psychosocial and physical domains of the quality of life respectively. In contrast to available literature, subjective fatigue was less common than expected. Based on these findings, we advise health-care providers to include balance training and risk of falls prevention strategies in the standard care of patients on HD and as it could improve other domains of the quality of life compared to conventional exercise training.

\section{Supplementary information}

Supplementary information accompanies this paper at https://doi.org/10. 1186/s12882-019-1671-9.

Additional file 1 Table S1: Between-groups analysis of functional performance on the dimensions of quality of life.

Additional file $\mathbf{2}$ Table $\mathbf{S 2}$ and S3: Associations between the objective measures of physical function and the risk of falls.

Additional file $\mathbf{3}$ Table S4: Between-groups analysis of the subcategories of EQ-5D on physical function.

\section{Abbreviations}

6MWT: Six-minute walking test; ADL: Activities of daily living; DFRl: Dialysis fall risk index; FICSIT: Frailty and injuries cooperative studies of intervention. technique; HD: Haemodialysis; HRQoL: Health-related quality of life (HRQoL); LLN: Lower limit of normal; MAP: Mean arterial pressure; STS: Sit-to-Stand

\section{Acknowledgements}

The authors are indebted to Isabel Van Dorpe for database management, and to the study nurses Elsie De Man and Kelly Rokegem for assistance with the questionnaires.

\section{Authors' contributions}

KW: writing of the manuscript, performing and coordinating the crosssectional study, approval of the manuscript. AVC: co-writing of the manuscript, supervising of the manuscript, approval of the manuscript. SE: supervising of the manuscript, approval of the manuscript. PC: supervising of the cross-sectional study and manuscript, approval of the manuscript. BC: supervising of the writing of the manuscript. EH: assessing the questionnaires, approval of the manuscript. WVB: supervising of the manuscript, project leader of the cross-sectional study, principal investigator approval of the manuscript. All authors read and approved the final manuscript.

Funding

This cross-sectional study was not funded. 


\section{Availability of data and materials}

As the full dataset is still being used for other analyses, it has not been anonymized yet. The datasets (without any identifying information) used and/or analysed during the current study are available from the corresponding author on reasonable request.

\section{Ethics approval and consent to participate}

This study is part of a larger study examining the prognostic determinants of mortality and HRQoL in patients with end-stage kidney disease. The study complies with the Declaration of Helsinki, was approved by the Ghent ethics committee (project number B670201525559) for the dialysis centres in Ghent university hospital and general hospitals of Aalst, Geraardsbergen, Wetteren and by the Antwerp ethics committee (project number B300201422642) for the dialysis centres in Antwerp university hospital, and written informed consent was obtained.

\section{Consent for publication}

Not applicable.

\section{Competing interests}

The authors declare that they have no competing interests.

\section{Author details}

'Department of Rehabilitation Sciences, Faculty of Medicine and Health Sciences, Ghent University, Corneel Heymanslaan 10, 9000 Ghent, Belgium. ${ }^{2}$ Department of Nephrology, University Hospitals Leuven, Leuven, Belgium. ${ }^{3}$ Laboratory of Experimental Medicine and Paediatrics, University of Antwerp, Antwerp, Belgium. ${ }^{4}$ Department of Internal Medicine, Renal Division, Ghent University Hospital, Ghent, Belgium.

Received: 26 April 2019 Accepted: 23 December 2019 Published online: 06 January 2020

\section{References}

1. Bučar Pajek M, Čuk I, Leskošek B, Mlinšek G, Buturović Ponikvar J, Pajek J. Six-minute walk test in renal failure patients: representative results, performance analysis and perceived dyspnea predictors. PLoS One. 2016; 11(3):e0150414.

2. Kemp GJ, Crowe AV, Anijeet HK, Gong QY, Bimson WE, Frostick SP, Bone JM, Bell GM, Roberts JN. Abnormal mitochondrial function and muscle wasting, but normal contractile efficiency, in haemodialysed patients studied noninvasively in vivo. Nephrol Dial Transplant. 2004;19(6):1520-7.

3. Sawant A, Garland SJ, House AA, Overend TJ. Morphological, electrophysiological, and metabolic characteristics of skeletal muscle in people with end-stage renal disease: a critical review. Physiother Can. 2011; 63(3):355-76.

4. Cupisti A, Capitanini A, Betti G, D'Alessandro C, Barsotti G. Assessment of habitual physical activity and energy expenditure in dialysis patients and relationships to nutritional parameters. Clin Nephrol. 2011;75(3):218-25.

5. Souweine JS, Kuster N, Chenine L, Rodriguez A, Patrier L, Morena M, Badia E, Chalabi L, Raynal N, Ohresser I, et al. Physical inactivity and protein energy wasting play independent roles in muscle weakness in maintenance haemodialysis patients. PLoS One. 2018;13(8):e0200061.

6. Abdel-Rahman EM, Turgut F, Turkmen K, Balogun RA. Falls in elderly hemodialysis patients. J Assoc Phys. 2011;104(10):829-38.

7. Alem AM, Sherrard DJ, Gillen DL, Weiss NS, Beresford SA, Heckbert SR, Wong C, Stehman-Breen C. Increased risk of hip fracture among patients with end-stage renal disease. Kidney Int. 2000;58(1):396-9.

8. Wang AY, Sherrington C, Toyama T, Gallagher MP, Cass A, Hirakawa Y, Li Q, Sukkar L, Snelling P, Jardine MJ. Muscle strength, mobility, quality of life and falls in patients on maintenance haemodialysis: A prospective study. Nephrol (Carlton, Vic). 2017;22(3):220-7.

9. Heiwe $\mathrm{S}$, Jacobson SH. Exercise training for adults with chronic kidney disease. Cochrane database Syst Rev. 2011;(10):Cd003236.

10. Altintepe L, Levendoglu F, Okudan N, Guney I, Savas Cilli A, Ugurlu H, Tonbul Z, Gokbel H, Turk S. Physical disability, psychological status, and health-related quality of life in older hemodialysis patients and agematched controls. Hemodial Int. 2006;10(3):260-6.

11. Gordon PL, Doyle JW, Johansen KL. Postdialysis fatigue is associated with sedentary behavior. Clin Nephrol. 2011;75(5):426-33.
12. Yong DS, Kwok AO, Wong DM, Suen MH, Chen WT, Tse DM. Symptom burden and quality of life in end-stage renal disease: a study of 179 patients on dialysis and palliative care. Palliat Med. 2009;23(2):111-9.

13. Ju A, Unruh M, Davison S, Dapueto J, Dew MA, Fluck R, Germain M, Jassal SV, Obrador G, O'Donoghue D, et al. Establishing a Core outcome measure for fatigue in patients on hemodialysis: a standardized outcomes in nephrology-hemodialysis (SONG-HD) consensus workshop report. Am J Kidney Dis. 2018;72(1):104-12.

14. Zuo M, Tang J, Xiang M, Long Q, Dai J, Hu X. Relationship between fatigue symptoms and subjective and objective indicators in hemodialysis patients. Int Urol Nephrol. 2018;50(7):1329-39.

15. Zyga S, Alikari V, Sachlas A, Fradelos EC, Stathoulis J, Panoutsopoulos G, Georgopoulou M, Theophilou P, Lavdaniti M. Assessment of Fatigue in End Stage Renal Disease Patients Undergoing Hemodialysis: Prevalence and Associated Factors. Med Arch (Sarajevo Bosn Herzegovina). 2015;69(6):37680.

16. Bohannon RW. Reference values for extremity muscle strength obtained by hand-held dynamometry from adults aged 20 to 79 years. Arch Phys Med Rehabil. 1997;78(1):26-32.

17. Vanpee G, Segers J, Van Mechelen H, Wouters P, Van den Berghe G, Hermans $G$, Gosselink R. The interobserver agreement of handheld dynamometry for muscle strength assessment in critically ill patients. Crit Care Med. 2011;39(8):1929-34.

18. Clinical assessment recommendations. Chicago (401 N. Michigan Ave., Chicago IL 60611-4267): The Society: American Society of Hand T; 1992.

19. Hermans G, Clerckx B, Vanhullebusch T, Segers J, Vanpee G, Robbeets C, Casaer MP, Wouters P, Gosselink R, Van Den Berghe G. Interobserver agreement of Medical Research Council sum-score and handgrip strength in the intensive care unit. Muscle Nerve. 2012;45(1):18-25.

20. Mathiowetz V, Kashman N, Volland G, Weber K, Dowe M, Rogers S. Grip and pinch strength: normative data for adults. Arch Phys Med Rehabil. 1985; 66(2):69-74.

21. Uszko-Lencer NHMK, Mesquita R, Janssen E, Werter C, Brunner-La Rocca H-P, Pitta F, Wouters EFM, Spruit MA. Reliability, construct validity and determinants of 6-minute walk test performance in patients with chronic heart failure. Int J Cardiol. 2017:240:285-90.

22. Duncan MJ, Mota J, Carvalho J, Nevill AM. Correction: an evaluation of prediction equations for the 6 minute walk test in healthy European adults aged 50-85 years. PLoS One. 2015;10(11):e0142463.

23. Spruit MA, Polkey MI, Celli B, Edwards LD, Watkins ML, Pinto-Plata V, Vestbo J, Calverley PM, Tal-Singer R, Agusti A, et al. Predicting outcomes from 6minute walk distance in chronic obstructive pulmonary disease. J Am Med Dir Assoc. 2012;13(3):291-7.

24. Bernabeu-Mora R, Medina-Mirapeix F, Llamazares-Herrán E, de Oliveira-Sousa SL, Sánchez-Martinez MP, Escolar-Reina P. The accuracy with which the 5 times sit-to-stand test, versus gait speed, can identify poor exercise tolerance in patients with COPD: a cross-sectional study. Med. 2016;95(35):e4740.

25. Kono K, Nishida Y, Yabe H, Moriyama Y, Mori T, Shiraki R, Sato T. Development and validation of a fall risk assessment index for dialysis patients. Clin Exp Nephrol. 2018;22(1):167-72.

26. Brzosko S, Hryszko T, Klopotowski M, Mysliwiec M. Validation of mini nutritional assessment scale in peritoneal dialysis patients. Arch Med Sci AMS. 2013;9(4):669-76.

27. Kopke S, Meyer G. The Tinetti test: Babylon in geriatric assessment. Z Gerontol Geriatr. 2006;39(4):288-91.

28. Thomas JI, Lane JV. A pilot study to explore the predictive validity of 4 measures of falls risk in frail elderly patients. Arch Phys Med Rehabil. 2005: 86(8):1636-40

29. Rossiter-Fornoff JE, Wolf SL, Wolfson LI, Buchner DM. A cross-sectional validation study of the FICSIT common data base static balance measures. Frailty and injuries: cooperative studies of intervention techniques. J Gerontol A Biol Sci Med Sci. 1995;50(6):M291-7.

30. Duncan RP, Leddy AL, Earhart GM. Five times sit-to-stand test performance in Parkinson's disease. Arch Phys Med Rehabil. 2011;92(9):1431-6.

31. Jones SE, Kon SS, Canavan JL, Patel MS, Clark AL, Nolan CM, Polkey MI, Man WD. The five-repetition sit-to-stand test as a functional outcome measure in COPD. Thorax. 2013;68(11):1015-20.

32. Buatois $S$, Miljkovic $D$, Manckoundia $P$, Gueguen $R$, Miget $P$, Vancon $G$, Perrin P, Benetos A. Five times sit to stand test is a predictor of recurrent falls in healthy community-living subjects aged 65 and older. J Am Geriatr Soc. 2008;56(8):1575-7. 
33. Janssen MF, Pickard AS, Golicki D, Gudex C, Niewada M, Scalone L, Swinburn P, Busschbach J. Measurement properties of the EQ-5D-5L compared to the EQ-5D-3L across eight patient groups: a multi-country study. Q Life Res. 2013;22(7):1717-27.

34. Crins MHP, Roorda LD, Smits N, de Vet HCW, Westhovens R, Cella D, Cook KF, Revicki D, van Leeuwen J, Boers M, et al. Calibration and validation of the Dutch-Flemish PROMIS pain interference item Bank in Patients with chronic pain. PLoS One. 2015;10(7):e0134094.

35. Morrisroe K, Stevens W, Huq M, Sahhar J, Ngian G-S, Zochling J, Roddy J, Proudman S, Nikpour M. Validity of the PROMIS-29 in a large Australian cohort of patients with systemic sclerosis. J Scleroderma Relat Dis. 2017;2(3): 188-95.

36. M Versteegh M, M Vermeulen K, M. A. A. Evers S, de Wit GA, Prenger, R A. Stolk E: Dutch tariff for the five-level version of EQ-5D. Value Health 2016, 19(4):343-352

37. Zazzeroni L, Pasquinelli G, Nanni E, Cremonini V, Rubbi I. Comparison of quality of life in patients undergoing hemodialysis and peritoneal Dialysis: a systematic review and meta-analysis. Kidney Blood Press Res. 2017;42(4): $717-27$.

38. Greenwood SA, Koufaki P, Rush R, Macdougall IC, Mercer TH. Exercise counselling practices for patients with chronic kidney disease in the UK: a renal multidisciplinary team perspective. Nephron Clinical practice. 2014; 128(1-2):67-72.

39. Obi Y, Qader H, Kovesdy CP, Kalantar-Zadeh K. Latest consensus and update on protein-energy wasting in chronic kidney disease. Current Opinion Clin Nutr Metab Care. 2015;18(3):254-62

40. Patel HP, Syddall HE, Jameson K, Robinson S, Denison H, Roberts HC, Edwards M, Dennison E, Cooper C, Aihie Sayer A. Prevalence of sarcopenia in community-dwelling older people in the UK using the European working group on sarcopenia in older people (EWGSOP) definition: findings from the Hertfordshire cohort study (HCS). Age Ageing. 2013;42(3):378-84.

41. Panjwani M, Truong LD, Eknoyan G. Membranous glomerulonephritis associated with inflammatory demyelinating peripheral neuropathies. Am J Kidney Dis. 1996;27(2):279-83.

42. Kaminski MR, Raspovic A, McMahon LP, Strippoli GF, Palmer SC, Ruospo M Dallimore S, Landorf KB. Risk factors for foot ulceration and lower extremity amputation in adults with end-stage renal disease on dialysis: a systematic review and meta-analysis. Nephrol Dial Transplant. 2015;30(10):1747-66.

43. Hajek A, König $\mathrm{H}-\mathrm{H}$. The association of falls with loneliness and social exclusion: evidence from the DEAS German ageing survey. BMC Geriatr. 2017;17(1):204

44. Manfredini F, Mallamaci F, D'Arrigo G, Baggetta R, Bolignano D, Torino C, Lamberti N, Bertoli S, Ciurlino D, Rocca-Rey L, et al. Exercise in patients on Dialysis: a multicenter, randomized clinical trial. J Am Soc Nephrol. 2017; 28(4):1259.

45. Carvalho EV, Reboredo MM, Gomes EP, Teixeira DR, Roberti NC, Mendes JO, Oliveira JC, Sanders-Pinheiro H, Pinheiro BV. Physical activity in daily life assessed by an accelerometer in kidney transplant recipients and hemodialysis patients. Transplant Proc. 2014;46(6):1713-7.

46. Pagels AA, Söderkvist BK, Medin C, Hylander B, Heiwe S. Health-related quality of life in different stages of chronic kidney disease and at initiation of dialysis treatment. Health Qual Life Outcomes. 2012;10(1):71.

47. Zelle DM, Klaassen G, van Adrichem E, Bakker SJ, Corpeleijn E, Navis G. Physical inactivity: a risk factor and target for intervention in renal care. Nat Rev Nephrol. 2017;13(3):152-68.

48. Lowney AC, Myles HT, Bristowe K, Lowney EL, Shepherd K, Murphy M, O'Brien T, Casserly L, McQuillan R, Plant WD, et al. Understanding what influences the health-related quality of life of hemodialysis patients: a collaborative study in England and Ireland. J Pain Symptom Manag. 2015; 50(6):778-85.

49. Herschbach $P$. The "well-being paradox" in quality-of-life research. Psychother Psychosom Med Psychol. 2002;52(3-4):141-50.

50. Hays RD, Spritzer KL, Schalet BD, Cella D. PROMIS -29 v2.0 profile physical and mental health summary scores. Qual Life Res. 2018;27(7):1885-91.

51. Austin $P C$, Steyerberg EW. The number of subjects per variable required in linear regression analyses. J Clin Epidemiol. 2015;68(6):627-36.

\section{Publisher's Note}

Springer Nature remains neutral with regard to jurisdictional claims in published maps and institutional affiliations.

Ready to submit your research? Choose BMC and benefit from:

- fast, convenient online submission

- thorough peer review by experienced researchers in your field

- rapid publication on acceptance

- support for research data, including large and complex data types

- gold Open Access which fosters wider collaboration and increased citations

- maximum visibility for your research: over $100 \mathrm{M}$ website views per year

At BMC, research is always in progress.

Learn more biomedcentral.com/submissions 